\title{
BMJ Open Do baby boomers feel healthier than earlier cohorts after retirement age? The Lausanne cohort Lc65+ study
}

\author{
Yves Henchoz, ${ }^{1}$ Armin von Gunten, ${ }^{2}$ Christophe Büla, ${ }^{3}$ \\ Laurence Seematter-Bagnoud, ${ }^{1}$ David Nanchen, ${ }^{4}$ Jean-Francois Démonet, ${ }^{5}$ \\ Juan-Manuel Blanco, ${ }^{1}$ Brigitte Santos-Eggimann ${ }^{1}$
}

To cite: Henchoz Y, von Gunten A, Büla C, et al. Do baby boomers feel healthier than earlier cohorts after retirement age? The Lausanne cohort LC65+ study. BMJ Open 2019:9:e025175. doi:10.1136/ bmjopen-2018-025175

- Prepublication history and additional material for this paper are available online. To view these files, please visit the journal online (http://dx.doi. org/10.1136/bmjopen-2018025175).

Received 4 July 2018

Revised 31 October 2018

Accepted 30 November 2018

Check for updates

(C) Author(s) (or their employer(s)) 2019. Re-use permitted under CC BY-NC. No commercial re-use. See rights and permissions. Published by BMJ.

${ }^{1}$ Institute of Social and Preventive Medicine, University of Lausanne Hospital Centre, Lausanne, Switzerland

${ }^{2}$ Service of Geriatric Psychiatry, Department of Psychiatry, University of Lausanne Hospital Centre, Lausanne, Switzerland ${ }^{3}$ Service of Geriatric Medicine and Geriatric Rehabilitation, University of Lausanne Hospital Center, Lausanne, Switzerland ${ }^{4}$ Department of Ambulatory Care and Community Medicine, University of Lausanne, Lausanne, Switzerland

${ }^{5}$ Leenaards Memory Centre, University of Lausanne Hospital Centre, Lausanne, Switzerland

Correspondence to

Dr Yves Henchoz;

yves.henchoz@chuv.ch

\section{ABSTRACT}

Objective Despite the popular belief that baby boomers are ageing in better health than previous generations, limited scientific evidence is available since baby boomers have turned retirement age only recently. This study aimed to compare self-reported health status at ages 65-70 years among three cohorts of older people born before, during and at the end (baby boomers) of the Second World War.

Design Repeated cross-sectional population-based study. Setting Community in a region of French-speaking Switzerland.

Participants Community-dwelling older adults who enrolled in the Lausanne cohort 65+ study at ages $65-70$ years in $2004(n=1561), 2009(n=1489)$ or 2014 $(\mathrm{n}=1678)$.

Outcomes Number of self-reported chronic conditions (from a list of 11) and chronic symptoms (from a list of 11); depressive symptoms; self-rated health (very good, good, average, poor or very poor); fear of disease (not afraid at all, barely afraid, a bit afraid, quite afraid or very afraid); self-perception of ageing; disability in basic and instrumental activities of daily living.

Results There was no significant difference between cohorts in the number of self-reported chronic conditions and chronic symptoms as well as the presence of difficulty in basic activities of daily living, depressive symptoms, fear of disease and negative self-perception of ageing. In women only, significant differences between cohorts were observed in self-rated health $(p=0.005)$ and disability in instrumental activities of daily living $(p=0.003)$, but these associations did not remain significant in logistic regression models adjusted for sociodemographic characteristics and unhealthy behaviours.

Conclusions Despite important sociodemographic differences between older baby boomers and earlier cohorts, most health indicators did not suggest any trend towards a compression of morbidity. Future studies comparing these three cohorts at more advanced age are required to further investigate whether differences emerge later in life.

\section{INTRODUCTION}

Life expectancy has risen by 3 months per year over the past century in economically developed countries. ${ }^{1}$ This remarkable gain

\section{Strengths and limitations of this study}

- The repeated cross-sectional design allowed comparing at 5-year intervals three representative samples of community-dwelling older men and women of similar age, with identical instruments and data collection process.

- Comparisons between cohorts could be adjusted for a substantial number of potential confounders.

- Comparisons between cohorts may reflect a cohort effect, a period effect or a combination of both effects.

- The baby boom cohort is representative of early members of this generation.

- Cohort differences may become more apparent at more advanced ages.

in longevity was driven by reductions in mortality at different ages over time. Until the 1920 s, medical advances aimed at curing infectious diseases mainly benefited survival in infants and children. ${ }^{2}$ From the second half of the 20th century, mortality reduction at older ages gradually became the main contributor to the increase in life expectancy. As a result of the epidemiological transition, the proportion of the population aged 65 years and over in Switzerland almost doubled from $9.6 \%$ in 1950 to $18.0 \%$ in $2015 .^{3}$ This increase will continue until 2030 as baby boomers (defined in this study as those born between 1944 and the mid-1960s) are turning 65. This demographic shift represents a major challenge to health systems worldwide and raises a key question whether new cohorts of older people will be and feel healthier than those who preceded them. ${ }^{4}$

Given the favourable context in which baby boomers grew up, the media frequently convey the idea that this generation will age more healthily than their earlier counterparts. ${ }^{5}$ The baby boom generation distinguishes itself from earlier generations because of its large 
size and its distinct socioeconomic characteristics such as lower rates of marriage, a higher proportion of women in the workforce, as well as increased racial and ethnic diversity. ${ }^{6}$ The prosperous period following the Second World War had noticeable social and economic impacts that improved baby boomers' access to education and health resources. Despite these advantages, the literature addressing the baby boom generation's health in adulthood provides contradictory observations. According to some studies, baby boomers rated their health more favourably than their predecessors, ${ }^{78}$ whereas others did not report a significant difference ${ }^{9-11}$ or even found worse results in baby boomers. ${ }^{12-15}$ Nevertheless, as early baby boomers began retiring in 2011, all aforementioned studies could not yet address health trends after age 65 . Advances in medical care for health conditions that affect most individuals only at an older age may still favour baby boomers compared with previous cohorts. ${ }^{10}$

This study aimed to investigate differences in the health status reported by community-dwelling older people enrolled in the Lausanne cohort $65+$ (Lc65+) population-based study in 2004, 2009 and 2014, who were born, respectively, before, during and at the end of the Second World War. Better self-reported health indicators were expected for baby boomers compared with their predecessors born 5 and 10 years earlier, respectively.

\section{METHODS}

\section{Study design and population}

The Lc65+ is a population-based study initiated in 2004 to investigate the manifestation and development of frailty after 65 years. The Lc65+ study enrolment plan was described in detail previously. ${ }^{16}$ As illustrated in figure 1, in 2004, 2009 and 2014, three samples were randomly selected from the community-dwelling population in Lausanne (the capital of Canton Vaud,
Switzerland) born, respectively, before (1934-1938, $\mathrm{n}=3236)$, during (1939-1943, $\mathrm{n}=3293$ ) and at the end (1944-1948, n=3796) of the Second World War. Place of residence (Lausanne) and year of birth were the only eligibility criteria. Participants living in an institution or unable to respond by themselves due to advanced dementia were excluded. Accounting for eligibility and exclusion criteria, the number of mailed enrolment questionnaires in 2004, 2009 and 2014 was, respectively, 3053, 3179 and 3655. Due to non-responses, refusals and further exclusions, the number of valid enrolment questionnaires was $1564(51.2 \%)$ in 2004, $1489(46.9 \%)$ in 2009 and $1678(46.0 \%)$ in 2014. For the present analysis, three participants in 2004 were excluded a posteriori due to cognitive inability. Compared with non-participants, participants did not differ in age or sex (online supplementary tables 1-3). Previous analyses of data from the first wave also indicated that participants' socioeconomic characteristics (nationality, marital status, place of birth, living arrangement, professional activity-data not shown) closely reflected the Lausanne general population in the same age category. ${ }^{16}$

\section{Patient and public involvement}

Participants in the Lc65+ cohort or the public were not involved in the design, recruitment or conduct of the study. However, a lay publication called 'Lettre de la Cohorte' informs annually participants in the Lc65+ study and their primary care physician about selected summary results from the study, health-related advice and information on the following research steps. In addition, a total of 1100 participants in the Lc65+ cohort as well as 300 health actors and professionals took part in the conference 'better understanding age-related frailty' held in Lausanne on 5 November 2013. 


\section{Measures}

The complete list of baseline assessments of the Lc65+ study has been described previously. ${ }^{16}$ The present study focused on data collected through the enrolment questionnaire.

\section{Chronic conditions}

To assess chronic conditions, participants were asked whether they were ever diagnosed by a physician with any of 11 common health conditions: hypertension, coronary heart disease, other heart diseases, stroke, diabetes mellitus, chronic respiratory disease, osteoporosis, arthritis, cancer, gastrointestinal ulcer and Parkinson's disease. The number of chronic conditions was categorised as ' 0 ', ' 1 ' or ' $\geq 2$ '.

\section{Chronic symptoms}

Respondents were asked whether or not they were disturbed by any of 11 chronic symptoms for at least 6 months: joint pain, back pain, chest pain (on exertion), dyspnoea, persistent cough, swollen legs, mental impairment (ie, memory gaps, difficulty concentrating or difficulty making decisions in daily life), dizziness or vertigo, skin problems (eg, eczema, psoriasis), stomach or intestine problems (including diarrhoea and constipation) and urinary incontinence.

This list was adapted from the Survey of Health, Ageing and Retirement in Europe (SHARE) ${ }^{17}$ The number of chronic symptoms was categorised as ' 0 ', ' 1 ' or ' $\geq 2$ '.

\section{Depressive symptoms}

The presence of depressive symptoms was defined as a positive response to any of the two following questions of the Primary Care Evaluation of Mental Disorders Procedure: 'During the past month, have you often been bothered by: (1) feeling down, depressed or hopeless?; (2) little interest or pleasure in doing things?' These two questions had a sensitivity of $96 \%$ and a specificity of $57 \%$ in diagnosing depression as compared with a standardised interview. ${ }^{18}$

\section{Self-rated health}

Self-rated health was reported as 'very good', 'good', 'average', 'poor' or 'very poor'. Because of low frequencies in the two poorest response choices, they were collapsed into 'poor/very poor'. A single question is a valuable indicator of how individuals perceive their overall health status, and a strong predictor of morbidity and mortality. ${ }^{19} 20$

\section{Fear of disease}

Fear of illness or worsening health was self-rated as "not afraid at all', 'barely afraid', 'a bit afraid', 'quite afraid' or 'very afraid'. Because of low frequencies in the two poorest response choices, they were collapsed into 'quite afraid/very afraid'.
Self-perception of ageing

The Attitudes Toward Own Aging Subscale of the Philadelphia Geriatric Center Morale Scale ${ }^{21}$ includes five items: (1) 'Things keep getting worse as I get older'; (2) 'I have as much pep as I did last year'; (3) 'As you get older, you are less useful'; (4) 'I am as happy now as I was when I was younger' and (5) 'As I get older, things are (better, worse or the same) as I thought they would be'. For the last item, a pilot study indicated that respondents often referred to their economic situation. In order to focus answers on health, the terms 'concerning health' were added to this item. Respondents were asked whether they agreed (scored 0) or disagreed (scored 1) with the first four items. According to the methodology used by Levy et $a l,{ }^{22}$ the last item was dichotomised as 'better' (scored 0 ) versus 'the same' or 'worse' (scored 1). After reversing the scores of the first and the third items, the sum of the five scores was dichotomised as positive (total score 0-2) versus negative (total score 3-5) self-perception of ageing.

\section{Difficulty with activities of daily living}

Basic activities of daily living (BADLs) were defined as dressing, bathing, eating, getting in/out of bed or an armchair and using the toilet. ${ }^{23}$ Instrumental activities of daily living (IADLs) were defined as shopping and routine tasks at home. Participants were asked whether they had had difficulty in performing BADLs and IADLs over the last 4 weeks. Response choices were 'no difficulty', 'difficulty with one or several activities but no help' or 'received help with one or several activities'.

\section{Covariates}

Respondents' date of birth and sex were obtained from the population office at the stage of sample selection (see section 'Study design and population'). Additional sociodemographic information was gathered by means of the enrolment questionnaire that provided information about country of birth ('Switzerland'; 'other country'), citizenship ('Swiss'; 'other'; 'Swiss plus another'), marital status ('single'; 'married'; 'separated/divorced'; 'widowed'), ever having children, living arrangement ('alone'; 'with others') and highest level of education achieved ('basic compulsory'; 'apprenticeship'; 'baccalaureate/professional degree'; 'university/high school'). Age was calculated from the date of birth and the date of receipt of the enrolment questionnaire.

Unhealthy behaviours included hazardous drinking, smoking, low physical activity and obesity. Hazardous drinking was assessed using the Alcohol Use Disorders Identification Test, Consumption, which provides a score ranging from 0 to 20 . Women and men who scored $\geq 4$ and $\geq 5$ points, respectively, were classified as hazardous drinkers. ${ }^{24}$ Smoking was defined as current smoking. Self-reported physical activity was defined as low if the three following criteria were met: $(1)<20 \mathrm{~min}$ of sport activity once a week; (2) <30 min of walking three times a week and (3) avoidance of climbing stairs or carrying light loads in daily activities. ${ }^{16}$ Body mass index (BMI) was 
calculated from self-reported height and weight. Obesity was defined as a BMI $\geq 30 \mathrm{~kg} / \mathrm{m}^{2}$.

\section{Statistical analyses}

A Kruskal-Wallis test was performed to determine if age differed significantly between cohorts. Proportions were compared using Pearson $\chi^{2}$ tests. Facing the omnibus nature of the $\chi^{2}$ test, adjusted residuals were calculated for each cell from the contingency table and those higher or lower than \pm 1.96 were identified. ${ }^{25}$ To adjust for multiple post hoc comparisons, the difference between observed and expected frequencies for a given cell was defined as statistically significant if adjusted residuals were greater or lower than \pm 2.39 for a contingency table of 3 cells, \pm 2.64 for 6 cells, \pm 2.77 for 9 cells, \pm 2.87 for 12 cells and \pm 2.94 for 15 cells, respectively.

Binary and ordinal logistic regression models were constructed to examine trends in health status across cohorts, adjusting for age and sex, and additionally for sociodemographic characteristics and unhealthy behaviours. For ordinal dependent variables, the proportional odds assumption posits that ORs are constant for every possible cut-offs on the dependent variable, which was tested using the Brant test. When the assumption was violated, a secondary analysis was performed where the proportional odds assumption was relaxed for the independent variables identified by the Brant test. ${ }^{26}$ Models constructed without interaction term between sex and cohort fitted the data better than those that included the interaction, based on Akaike information criterion and Bayesian information criterion. Furthermore, none of the interaction terms was significant in any of the models. Therefore, only main effects were included.

Analyses were conducted using Stata V.14.0 software (StataCorp). Significance was set at $\mathrm{p}<0.05$, with Bonferroni adjustment for multiple testing.

\section{RESULTS}

\section{Sociodemographic characteristics of the cohorts}

Table 1 displays and compares sex-specific sociodemographic characteristics of prewar, war and baby boom cohorts. Significant differences between cohorts were observed in marital status $(\mathrm{p}<0.001)$ and education $(\mathrm{p}<0.001)$ among women, and in citizenship $(\mathrm{p}=0.002)$, marital status $(\mathrm{p}=0.004)$, living arrangement $(\mathrm{p}=0.002)$ and education $(\mathrm{p}<0.001)$ among men. Inspection of adjusted residuals indicated an increase across cohorts in the level of education, a trend in marital status towards fewer marriages, more separations or divorces and less widowhood (women only), an increase in the proportion of men living alone and an increase in the proportion of Swiss male participants with dual nationality. Unhealthy behaviours (hazardous drinking, currently smoking, low physical activity and obesity) did not differ significantly between cohorts.

\section{Health status of the cohorts}

The sex-specific unadjusted health status of respondents from prewar, war and baby boom cohorts is detailed in table 2. In men, no significant difference between cohorts was observed in any health outcome measures. In women from the prewar cohort, self-rated health indicated a lower than expected proportion of 'very good' answers (observed: 13.6\%; expected: $16.8 \%$; $\mathrm{p}=0.005$ ). Difficulty in IADL also differed across cohorts $(\mathrm{p}=0.003)$, with higher than expected proportion of 'no difficulty' answers (observed: 88.7\%; expected: 85.6\%) and lower than expected proportion of 'difficulty but no help' answers (observed: 5.6\%; expected: $8.7 \%$ ) in women from the war cohort.

\section{Logistic regression models}

Table 3 shows the results of binary and ordinal logistic regression models. Self-rated health was better in both baby boomers $(\mathrm{OR}=0.81 ; \mathrm{p}=0.001)$ and the war cohort $(\mathrm{OR}=0.81 ; \mathrm{p}=0.002)$ as compared with the prewar cohort. These associations were no more significant at the Bonferroni-adjusted significance level $(p<0.006)$ when adjusting for sociodemographic characteristics and unhealthy behaviours (baby boomers: $\mathrm{OR}=0.84 ; \mathrm{p}=0.019$, war cohort: $\mathrm{OR}=0.83 ; \mathrm{p}=0.017$ ). There was no significant cohort effect on the number of chronic conditions and chronic symptoms, the presence of depressive symptoms, fear of disease, self-perception of ageing and difficulty in BADL and IADL. According to the Brant test, the proportional odds assumption was not violated when the dependent variable was self-rated health (partially adjusted model: $p=0.278$; fully adjusted model: $p=0.458$ ). As the proportional odds assumption was violated for the fear of illness variable $(\mathrm{p}<0.001$ for partially and fully adjusted models), a secondary analysis allowing odds ratios of independent variables identified by the Brant test to vary for each cut-off on fear of illness was performed. Results did not show any significant cohort effect.

\section{DISCUSSION}

\section{Main findings}

The present study sought to compare self-reported health status at ages $65-70$ years in baby boomers and peers from cohorts born 5 years and 10 years earlier. Results from this study seriously challenge the widely held belief that baby boomers are ageing in better health. Although baby boomers rated their health more favourably on average than their counterparts born before the Second World War, their ratings were comparable to those of the war cohort. Furthermore, trends in chronic conditions, chronic symptoms, depressive symptoms, fear of disease, self-perception of ageing and difficulty in activities of daily living did not provide evidence that would support a compression of morbidity (ie, a reduced amount of time spent in poor health at the end of life through postponement of morbidity ${ }^{27}$ ). These findings are of utmost importance for health systems planning. Given the challenges posed by population ageing and baby boomers retirement, overly optimistic projections may place a tremendous burden on societies by 2030 . 
Table 1 Characteristics of community-dwelling older women and men from three cohorts of the Lausanne cohort $65+$ study

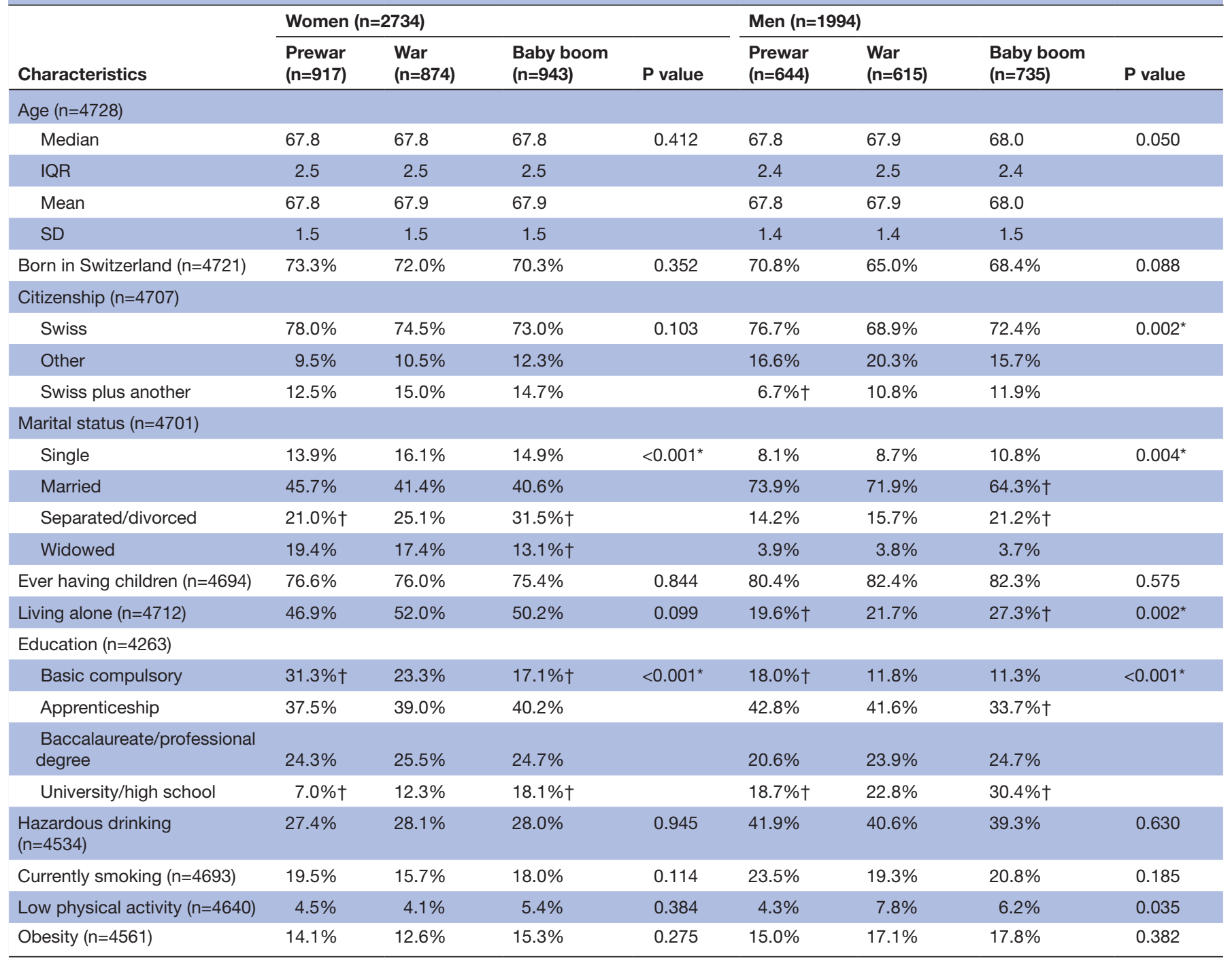

*Significant $\chi^{2}$ test (significance set at $\mathrm{p}<0.005$ after Bonferroni adjustment).

†Significantly higher/lower observed than expected frequencies after accounting for multiple testing.

\section{Sociodemographic characteristics and health status of the cohorts}

Sociodemographic characteristics observed in the present sample are consistent with previous studies indicating better access to education and a shift in marital status in baby boomers compared with previous generations. ${ }^{6}$ The difference between prewar and baby boom cohorts was most evident among women, as the proportion with basic compulsory education was almost halved and the proportion with university/high school degree more than doubled. Although higher educational attainment is strongly associated with a favourable health status, ${ }^{28}$ this study emphasises that this link might be counterbalanced by other factors. Among these factors, marital status deserves special attention, as it seems to play an important role. Indeed, according to the Health and Retirement Study, female baby boomers aged 51-60 years in 2006 had higher divorce rates than their peers in 1992, and being married was associated with lower disease risk and fewer functional limitations. ${ }^{29}$ Similarly, from 1980 to 2009 Lin et al reported an increasing proportion of unmarried adults aged 45-63 years, and identified them as a vulnerable subgroup in terms of economic disadvantage, poor health and loneliness. ${ }^{30}$ In the present study, the coexistence of health-promoting and health-impairing sociodemographic trends across cohorts likely explains results that showed only slight differences after adjustment for sociodemographic characteristics.

A significant contribution of the current study is also to show that the proportion of women reporting "no difficulty' in IADL was highest in the war cohort rather than in baby boomers. Although this result may seem counterintuitive, it is in line with those of a recent study on the association between prenatal exposure to the Second World War and health at the ages of 50-70 years. ${ }^{31}$ Using data from the SHARE, the authors reported no substantial negative effect of war exposure, and even a better health among exposed women. Further analyses suggested that 
Table 2 Self-reported health status among community-dwelling older women and men from three cohorts of the Lausanne cohort 65+ study

\begin{tabular}{|c|c|c|c|c|c|c|c|c|}
\hline \multirow[b]{2}{*}{ Characteristics } & \multicolumn{4}{|c|}{ Women $(n=2734)$} & \multicolumn{4}{|c|}{ Men $(n=1994)$} \\
\hline & $\begin{array}{l}\text { Prewar } \\
(n=917), \%\end{array}$ & $\begin{array}{l}\text { War } \\
(n=874), \%\end{array}$ & $\begin{array}{l}\text { Baby boom } \\
(n=943), \%\end{array}$ & $P$ value & $\begin{array}{l}\text { Prewar } \\
(n=644), \%\end{array}$ & $\begin{array}{l}\text { War } \\
(n=615), \%\end{array}$ & $\begin{array}{l}\text { Baby boom } \\
(n=735), \%\end{array}$ & $P$ value \\
\hline \multicolumn{9}{|c|}{ Chronic conditions ( $n=4701)$} \\
\hline 0 & 22.1 & 22.4 & 23.1 & 0.533 & 28.4 & 24.1 & 26.5 & 0.501 \\
\hline 1 & 34.5 & 37.8 & 35.2 & & 35.9 & 36.7 & 35.7 & \\
\hline$\geq 2$ & 43.4 & 39.8 & 41.7 & & 35.6 & 39.2 & 37.8 & \\
\hline \multicolumn{9}{|c|}{ Chronic symptoms $(n=4656)$} \\
\hline 0 & 16.6 & 19.3 & 18.9 & 0.408 & 27.9 & 27.3 & 30.4 & 0.379 \\
\hline 1 & 26.8 & 26.7 & 24.4 & & 27.6 & 31.6 & 28.7 & \\
\hline$\geq 2$ & 56.6 & 54.1 & 56.8 & & 44.4 & 41.2 & 40.9 & \\
\hline $\begin{array}{l}\text { Depressive symptoms } \\
(n=4648)\end{array}$ & 29.9 & 25.3 & 30.8 & 0.023 & 20.1 & 19.0 & 17.8 & 0.567 \\
\hline \multicolumn{9}{|c|}{ Self-rated health $(n=4714)$} \\
\hline Very good & $13.6 \dagger$ & 17.6 & 19.1 & $0.005^{*}$ & 15.0 & 16.3 & 19.2 & 0.152 \\
\hline Good & 48.6 & 50.8 & 45.9 & & 48.4 & 50.5 & 48.8 & \\
\hline Average & 31.2 & 27.4 & 28.8 & & 31.7 & 26.9 & 26.2 & \\
\hline Poor/very poor & 6.7 & 4.3 & 6.2 & & 5.0 & 6.4 & 5.7 & \\
\hline \multicolumn{9}{|l|}{ Fear of disease $(n=4680)$} \\
\hline Not afraid at all & 26.9 & 24.0 & 21.7 & 0.008 & 29.9 & 27.3 & 29.4 & 0.225 \\
\hline Barely afraid & 20.5 & 27.4 & 26.4 & & 21.1 & 27.3 & 25.2 & \\
\hline A bit afraid & 34.4 & 33.0 & 34.4 & & 37.6 & 33.2 & 33.7 & \\
\hline $\begin{array}{l}\text { Quite afraid/very } \\
\text { afraid }\end{array}$ & 18.2 & 15.6 & 17.5 & & 11.4 & 12.3 & 11.7 & \\
\hline \multicolumn{9}{|c|}{ Self-perception of ageing $(n=4224)$} \\
\hline Positive (score 0-2) & 60.6 & 60.6 & 58.1 & 0.490 & 62.4 & 57.8 & 61.4 & 0.254 \\
\hline $\begin{array}{l}\text { Negative (score } \\
3-5)\end{array}$ & 39.4 & 39.4 & 41.9 & & 37.6 & 42.2 & 38.6 & \\
\hline \multicolumn{9}{|c|}{ Difficulty in BADL $(n=4688)$} \\
\hline No difficulty & 91.2 & 93.5 & 91.8 & 0.458 & 92.2 & 91.3 & 91.2 & 0.882 \\
\hline $\begin{array}{l}\text { Difficulty but no } \\
\text { help }\end{array}$ & 7.2 & 5.4 & 6.5 & & 5.6 & 6.6 & 6.9 & \\
\hline Received help & 1.6 & 1.2 & 1.7 & & 2.2 & 2.1 & 1.9 & \\
\hline \multicolumn{9}{|c|}{ Difficulty in IADL $(n=4687)$} \\
\hline No difficulty & 83.5 & $88.7 \dagger$ & 84.8 & $0.003^{*}$ & 93.0 & 90.8 & 92.6 & 0.519 \\
\hline $\begin{array}{l}\text { Difficulty but no } \\
\text { help }\end{array}$ & 10.4 & $5.6 \dagger$ & 9.8 & & 4.4 & 4.9 & 4.4 & \\
\hline Received help & 6.1 & 5.6 & 5.3 & & 2.7 & 4.3 & 3.0 & \\
\hline
\end{tabular}

${ }^{*}$ Significant $\chi^{2}$ test (significance set at $p<0.006$ after Bonferroni adjustment).

†Significantly higher/lower observed than expected frequencies after accounting for multiple testing.

$B A D L$, basic activities of daily living; IADL, instrumental activities of daily living.

this was due to selective mortality at young ages and to selective fertility (ie, healthier individuals were more likely to give birth during the war). In the present study, another explanation may be that 7 in 10 participants were born in Switzerland whose economy and society were affected by the war but whose neutral status protected against extreme circumstances such as military hostilities and persecutions.

Strengths and limitations of the study

A clear strength of this study is the repeated cross-sectional design that allowed comparing at 5-year intervals 
Table 3 Logistic regression models for trends in health status among community-dwelling older women and men from three cohorts of the Lausanne cohort $65+$ study

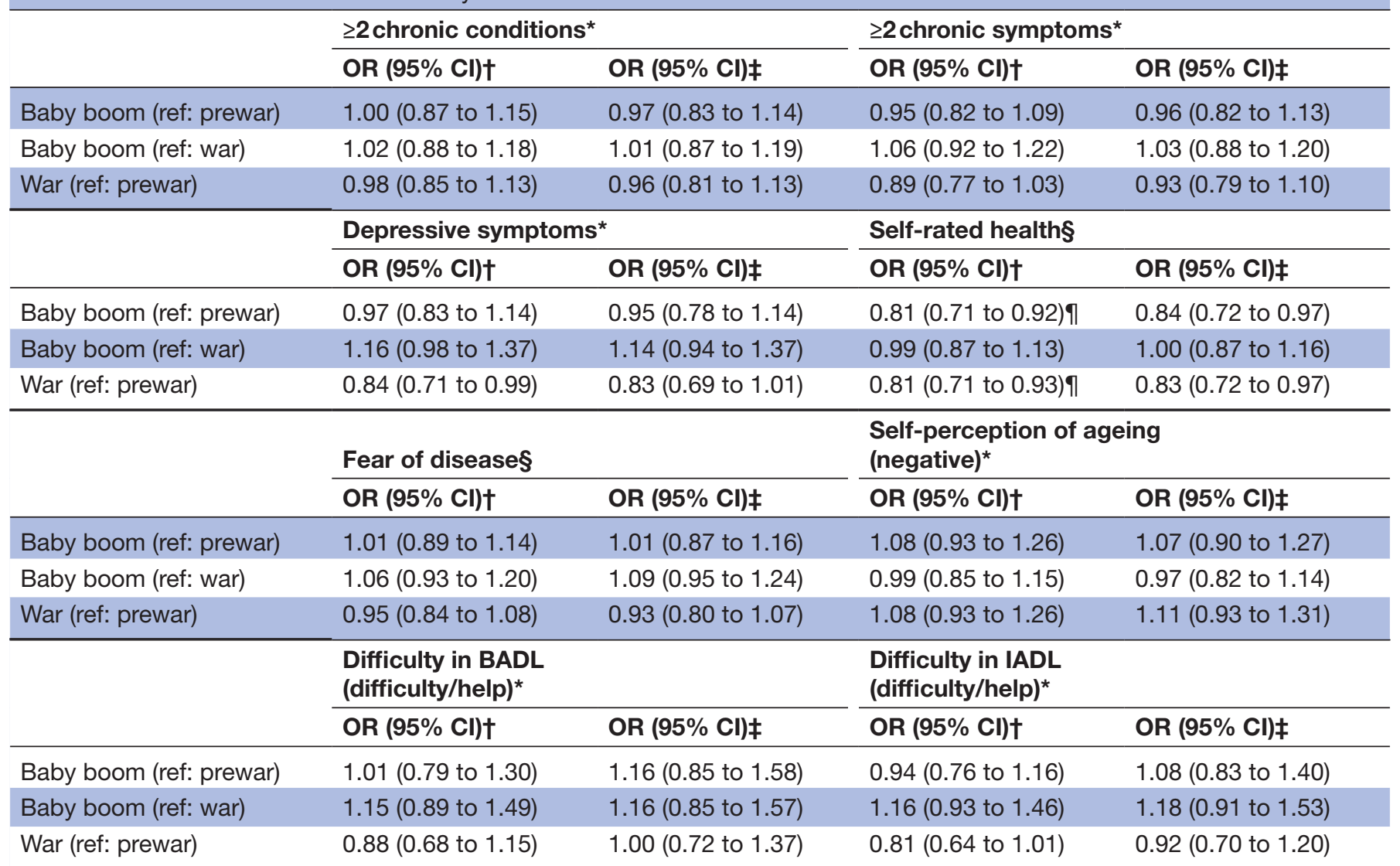

${ }^{*}$ Binary logistic regression $(0=$ good health, $1=$ poor health).

†Adjusted for age and sex.

$\ddagger$ Adjusted for age, sex, citizenship, marital status, education, hazardous drinking, currently smoking, low physical activity and obesity.

$\S$ Ordinal logistic regression (higher scores reflect poorer health).

ๆSignificant association (significance set at $\mathrm{p}<0.006$ after Bonferroni adjustment).

BADL, basic activities of daily living; IADL, instrumental activities of daily living.

three representative samples of community-dwelling older men and women of similar age, with identical instruments and data collection process, as well as to adjusting for a number of potential confounders. Nevertheless, several limitations should be mentioned. First, the sociocultural, economic and technological context may have been different in 2004, 2009 and 2014. Comparisons between samples may hence reflect a cohort effect (ie, being part of the prewar, war or baby boom sample), a period effect (being assessed in 2004, 2009 or 2014) or a combination of both effects. Statistical techniques such as age-period-cohort modelling have been developed for decades, but there is still substantial controversy around their ability to overpass the exact linear dependency of age, period and cohort (cohort=period-age) ${ }^{32}$ Furthermore, whether retired baby boomers feel healthier than earlier cohorts at the same age depends on the cumulative effect of period and cohort, which limits the usefulness of distinguishing their specific effects. Second, the baby boom cohort is representative of early members of this generation. The next decades will show if late baby boomers will have a better health status than early baby boomers. Furthermore, larger intervals between cohorts may uncover differences that the present study could not capture with 5-year intervals. Nevertheless, these intervals were sufficient to observe several differences between cohorts in sociodemographic characteristics. Third, although the cohorts compared in the present study were older than baby boom cohorts in any previous study, age-related losses may still be insufficient to translate into cohort differences that may become apparent only at more advanced ages. Finally, no normative health data were available to verify if external validity in terms of age, sex and socioeconomic characteristics can be generalised to health outcomes.

\section{CONCLUSION}

Contrary to popular belief, the present study does not provide evidence for a better self-reported health at ages 65-70 years in baby boomers than in earlier cohorts. Despite a slight trend in reporting better self-rated health, other data indicate that baby boomers do not feel healthier than previous cohorts did in terms of chronic 
conditions, chronic symptoms, depressive symptoms, fear of disease, self-perception of ageing and difficulty in activities of daily living. Nevertheless, it is still possible that protective factors, to which baby boomers were particularly exposed, such as prevention of at-risk behaviours and technological advances, will promote their health at an older age. Future studies will also show whether late baby boomers will feel healthier than early baby boomers at retirement age.

Acknowledgements The authors thank Alain Pécoud, Peter Vollenweider and Gérard Waeber for their support to the LC65+ study and their advice.

Contributors YH did the statistical analyses and drafted the manuscript. BS-E contributed to the conception of the questionnaire and to the data collection. $\mathrm{YH}$, AV-G, CB, LS-B, DN, J-FD, J-MB and BS-E contributed to the study concept and design, to the interpretation of data, to the critical review of the manuscript and approved the final version.

Funding The Lc65+ study has been supported by University of Lausanne Hospital Centre; University of Lausanne Department of Ambulatory Care and Community Medicine; Canton de Vaud Department of Public Health; City of Lausanne; Loterie Romande (research grant 2006-2008); Lausanne University Faculty of Biology and Medicine (multidisciplinary research grant 2006); Swiss National Foundation for Scientific Research (grant 3247B0-120795/1) and Fondation Médecine Sociale et Préventive, Lausanne.

Disclaimer The sponsors had no role in the design, execution, analysis and interpretation of data or writing of the study

Competing interests None declared.

Patient consent for publication Not required.

Ethics approval The protocol was approved by the Ethics Committee of the Faculty of Biology and Medicine of the University of Lausanne (19/04).

Provenance and peer review Not commissioned; externally peer reviewed. Data sharing statement The authors do not have permission to share data.

Open access This is an open access article distributed in accordance with the Creative Commons Attribution Non Commercial (CC BY-NC 4.0) license, which permits others to distribute, remix, adapt, build upon this work non-commercially, and license their derivative works on different terms, provided the original work is properly cited, appropriate credit is given, any changes made indicated, and the use is non-commercial. See: http://creativecommons.org/licenses/by-nc/4.0/.

\section{REFERENCES}

1. Oeppen J, Vaupel JW. Demography. Broken limits to life expectancy. Science 2002;296:1029-31.

2. Christensen $\mathrm{K}$, Doblhammer G, Rau R, et al. Ageing populations: the challenges ahead. Lancet 2009;374:1196-208.

3. Federal Statistical Office. Federal Population Census (1850-2000) \& Population Structure Indicators (1970-2015).

4. Knickman JR, Snell EK, The SEK. The 2030 problem: caring for aging baby boomers. Health Serv Res 2002;37:849-84.

5. Rambal J. Les papy-boomers, génération sans partage. Le Temps, 2016.

6. Frey WH. Baby Boomers and the New Demographics of America's Seniors. Generations 2010;34:28-37.

7. Martin LG, Schoeni RF, Freedman VA, et al. Feeling better? Trends in general health status. J Gerontol B Psychol Sci Soc Sci 2007;62:S11-S21.
8. Martin LG, Freedman VA, Schoeni RF, et al. Health and functioning among baby boomers approaching 60. J Gerontol B Psychol Sci Soc Sci 2009;64:369-77.

9. Badley EM, Canizares M, Perruccio AV, et al. Benefits gained, benefits lost: comparing baby boomers to other generations in a longitudinal cohort study of self-rated health. Milbank $Q$ 2015;93:40-72.

10. Madrian B, Mitchell OS, Soldo BJ. Are baby boomers living well longer? Redefining retirement: How will boomers fare? New York: Oxford University Press 2007.

11. Rice NE, Lang IA, Henley W, et al. Baby boomers nearing retirement: the healthiest generation? Rejuvenation Res 2010;13:105-14.

12. Soldo BJ, Mitchell OS, Tfaily R, et al. Cross-cohort differences in health on the verge of retirement. Redefining retirement: How will boomers fare? New York: Oxford University Press, 2007.

13. Zack MM, Moriarty DG, Stroup DF, et al. Worsening trends in adult health-related quality of life and self-rated health-United States, 1993-2001. Public Health Rep 2004;119:493-505.

14. Chen $\mathrm{H}$, Cohen $\mathrm{P}$, Kasen $\mathrm{S}$. Cohort differences in self-rated health: evidence from a three-decade, community-based, longitudinal study of women. Am J Epidemiol 2007;166:439-46.

15. King DE, Matheson E, Chirina S, et al. The status of baby boomers' health in the United States: the healthiest generation? JAMA Intern Med 2013;173:385-6.

16. Santos-Eggimann B, Karmaniola A, Seematter-Bagnoud L, et al. The Lausanne cohort Lc65+: a population-based prospective study of the manifestations, determinants and outcomes of frailty. BMC Geriatr 2008;8:20.

17. Alcser KH, Benson G, Börsch-Supan A, et al. The Survey of Health, Aging, and Retirement in Europe-Methodology. Manheim: Mannheim Research Institute for the Economics of. Aging 2005:175.

18. Whooley MA, Avins AL, Miranda J, et al. Case-finding instruments for depression. Two questions are as good as many. J Gen Intern Med 1997;12:439-45.

19. Fayers PM, Sprangers MA. Understanding self-rated health. Lancet 2002;359:187-8.

20. Jylhä M. What is self-rated health and why does it predict mortality? Towards a unified conceptual model. Soc Sci Med 2009;69:307-16.

21. Lawton MP. The Philadelphia Geriatric Center Morale Scale: a revision. J Gerontol 1975;30:85-9.

22. Levy BR, Slade MD, Kunkel SR, et al. Longevity increased by positive self-perceptions of aging. J Pers Soc Psychol 2002;83:261-70.

23. Katz S, Downs TD, Cash HR, et al. Progress in development of the index of ADL. Gerontologist 1970;10:20-30.

24. Gual A, Segura L, Contel M, et al. Audit-3 and audit-4: effectiveness of two short forms of the alcohol use disorders identification test. Alcohol Alcohol 2002;37:591-6.

25. Sharpe D. Your chi-square test is statistically significant: now what? Pract Assess Res Eval 2015;20:1-10.

26. Williams R. GEneralized ordered logit/partial proportional odds models for ordinal dependent variables. Stata J 2006;6:58-82.

27. Chatterji S, Byles J, Cutler D, et al. Health, functioning, and disability in older adults--present status and future implications. Lancet 2015;385:563-75.

28. Kawachi I, Adler NE, Dow WH. Money, schooling, and health: Mechanisms and causal evidence. Ann N Y Acad Sci 2010;1186:56-68.

29. Newton NJ, Ryan LH, King RT, et al. Cohort differences in the marriage-health relationship for midlife women. Soc Sci Med 2014;116:64-72.

30. Lin SF, Beck AN, Finch BK, et al. Trends in US older adult disability: exploring age, period, and cohort effects. Am J Public Health 2012;102:2157-63.

31. van Ewijk R, Lindeboom M. Why people born during World War II are healthier. Discussion Papers. Amsterdam: Gutenberg School of Management and Economics JG-UM. VU. 2017.

32. Bijlsma MJ. A hot topic and a futile quest? The recent discussion on age-period-cohort analysis. Demotrends 2014. 